\title{
The expression of vascular endothelial growth factor determines the efficacy of post-operative adjuvant chemotherapy using oral fluoropyrimidines in stage II or III colorectal cancer
}

\author{
YUTAKA OGATA, KEIKO MATONO, TOMOAKI MIZOBE, NOBUYA ISHIBASHI, SHINJIRO MORI, \\ YOSHITO AKAGI, SATORU IKEDA, HIROYUKI OZASA, HIDETSUGU MURAKAMI and KAZUO SHIROUZU
}

Department of Surgery, Kurume University School of Medicine, Kurume, Fukuoka 830-0011, Japan

Received November 30, 2005; Accepted January 17, 2006

\begin{abstract}
The aim of this study was to determine any correlation between the efficacy of post-operative adjuvant chemotherapy using oral fluoropyrimidines and the vascular endothelial growth factor (VEGF) expression in primary colorectal cancer tissues. The data were reviewed retrospectively on 342 patients with colorectal cancer at stage II or III, who underwent potentially curative resection between 1988 and 1998. Of these, 225 received post-operative administration of oral fluoropyrimidines such as UFT and 5'DFUR, while the other 117 patients underwent surgery alone. Immunostaining for VEGF was performed using colorectal tumours. Overall, VEGF was positively expressed in primary tumour cells in $48 \%$ of patients. The disease-free survival rate and the overall survival rate in the chemotherapy group were higher than those in the surgery-alone group, although not significantly. However, the disease-free survival rate and the overall survival rate were similar between the two groups in patients with a tumour positive for VEGF. Multivariate analysis revealed that the VEGF expression was an independent factor for post-operative recurrence, and the VEGF expression and post-operative adjuvant chemotherapy were an independent factor for overall survival, in addition to the lymph node metastasis and the venous invasion. In conclusion, the efficacy of post-operative adjuvant chemotherapy using oral fluoropyrimidines may not be as great for patients with a tumour positive for VEGF having a greater risk of post-operative recurrence. The results support further investigation on efficacy of molecular targeting therapy for VEGF in combination with oral fluoropyrimidines as post-operative adjuvant therapy in colorectal cancer positive for VEGF.
\end{abstract}

Correspondence to: Dr Yutaka Ogata, Department of Surgery, Kurume University School of Medicine, 67 Asahi-machi, Kurume, Fukuoka 830-0011, Japan

E-mail: yogata@med.kurume-u.ac.jp

Key words: vascular endothelial growth factor expression, immunohistochemistry, post-operative adjuvant chemotherapy, oral fluoropyrimidine, colorectal carcinoma, molecular targeting therapy

\section{Introduction}

Colorectal cancer remains one of the leading causes of death in the world. The mainstay for treatment of colorectal cancer with curative intent is surgical resection. In node-positive or stage III patients, surgery-alone offers curability to $~ 50 \%$ of patients treated (1). Thus, addressing the high risk of recurrence involves the use of chemotherapy, immunotherapy, or molecular targeting therapy after surgical removal of the primary lesion.

Worldwide, infusion of 5-fluorouracil plus leucovorin (5-FU/LV) combination chemotherapy has been considered to be standard for stage III colon cancer for the past decade (2), whereas the current evidence does not support the use of adjuvant chemotherapy for all patients with stage II disease (3). Recently, FOLFOX (added oxaliplatin to bolus plus infusion 5 -FU/LV) was reportedly more effective than 5-FU/LV in stage II or III colon cancer (4).

In Japan, since the 1980s, oral 5-FU derivatives (fluoropyrimidines) such as UFT (1:tegafur + 4:uracil) and 5'-deoxy5-fluorouridine (5'-DFUR), an intermediate of capecitabine, have been used as post-operative adjuvant chemotherapy for colorectal cancer. A recent meta-analysis has reported that surgery combined with oral fluoropyrimidines was more effective in preventing recurrence in patients with colorectal cancer at stage II or III rather than surgery alone $(5,6)$. Moreover, it has been shown that the post-operative adjuvant chemotherapy using capecitabine or UFT/oral LV is not inferior to bolus 5-FU/LV (Twelves C, et al, Proc ASCO, abs. 3521, 2005) (Wolmark N, et al, J Clin Oncol ASCO 22: $3508,2004)$. In general, chemotherapy using oral fluoropyrimidines, when compared to that using intravenous 5FU/LV, or its combination with irinotecan or oxaliplatin $(7,8)$, has been characterized by a lower incidence of adverse effects, especially infrequent adverse effects of grade 3 or higher (9). This is the reason that chemotherapy using oral fluoropyrimidines can be continued on an out-patient basis without detriment to the patients' quality of life (QOL). For patients, these are critical benefits of the therapy using oral fluoropyrimidines. It is therefore important to know which patients do not respond to oral fluoropyrimidines, in order to employ more intensive chemotherapy or some effective molecular targeting therapy, for improving the clinical efficacy of treatment and for improving the patient's QOL. 
Table I. Background of the patients and the tumours.

\begin{tabular}{lcccccccc}
\hline & $\begin{array}{c}\text { Age }^{\mathrm{a}} \\
(\mathrm{mean} \pm \mathrm{SD})\end{array}$ & $\begin{array}{c}\text { Sex } \\
(\mathrm{M} / \mathrm{F})\end{array}$ & $\begin{array}{c}\text { Stage } \\
(\mathrm{II} / \mathrm{III})\end{array}$ & $\begin{array}{c}\text { Location } \\
(\mathrm{R} / \mathrm{C})\end{array}$ & $\begin{array}{c}\text { N factor } \\
(\mathrm{N} 1 / \mathrm{N} 2)\end{array}$ & $\begin{array}{c}\text { TIO } \\
(-/+)\end{array}$ & $\begin{array}{c}\text { Ly } \\
(-/+)\end{array}$ & $\begin{array}{c}\mathrm{V} \\
(-/+)\end{array}$ \\
\hline $\begin{array}{l}\text { Surgery-alone } \\
(\mathrm{n}=117)\end{array}$ & $66.1 \pm 10.6$ & $71 / 46$ & $59 / 58$ & $52 / 65$ & $43 / 15$ & $99 / 18$ & $64 / 53$ & $66 / 51$ \\
$\begin{array}{l}\text { Chemotherapy } \\
(\mathrm{n}=225)\end{array}$ & $61.7 \pm 10.2$ & $139 / 86$ & $97 / 128$ & $98 / 127$ & $83 / 45$ & $204 / 21$ & $122 / 103$ & $138 / 87$ \\
\hline
\end{tabular}

${ }^{\mathrm{a}} \mathrm{p}<0.001$; M, male; F, female; Stage, pathological stage according to the U1CC criteria; R, rectum; C, colon; TIO, tumour invasion to adjacent organs; Ly, lymphatic invasion; V, venous invasion.

Vascular endothelial growth factor (VEGF), a diffusible glycoprotein produced by normal and neoplastic cells, has a crucial role in physiological and pathological angiogenesis (10), and has been implicated in tumour growth and metastasis (11). We have also previously reported VEGF expression in colorectal cancer as a factor of poor prognosis (12). VEGF blockade, alone or in combination with chemotherapeutic agents, is being tested in a number of clinical trials $(13,14)$, including the first successful phase III trial (15). In the present study, we investigated the correlation between the efficacy of post-operative adjuvant chemotherapy using oral fluoropyrimidines and the VEGF immunoexpression in colorectal cancer tissues, and discuss the application of molecular targeting therapy for VEGF as post-operative adjuvant therapy.

\section{Patients and methods}

Patients and post-operative adjuvant chemotherapy. Among the 487 patients with a pathological stage II or III colorectal cancer according to the UICC classification of colorectal carcinomas who underwent potentially curative resection (R0) with lymphadenectomy including the mesenteric lymph nodes at Kurume University Hospital between 1988 and 1998, 342 patients were enrolled in this retrospective study. When the distal margin of clinical stage II or III rectal cancer is located below the peritoneal reflection, pre-operative adjuvant radiotherapy was indicated in our institute, and these patients were excluded from this study. The other exclusion criteria were age more than 80 years, pre-operative chemotherapy, any immunotherapy, any other radiotherapy and post-operative chemotherapy except oral fluoropyrimidines. Post-operative adjuvant chemotherapy using oral fluoropyrimidines such as UFT and 5'-DFUR was performed in 225 patients (chemotherapy group). The other 117 patients underwent surgery alone (surgery-alone group). UFT and 5'DUUR was administered periodically for 1 year when recurrence did not occur. The chemotherapy started from 2 to 4 weeks after surgery. The oral dosages were $500 \mathrm{mg} / \mathrm{m}^{2} /$ day 5 '-DFUR, and $250 \mathrm{mg} / \mathrm{m}^{2} /$ day UFT. The main reason for surgery alone was patient's choice after informed consent.

Follow-up. Follow-up investigations were performed through out-patient visits, by letter, and by telephone, and the most recent date of contact for each patient was regarded as the final date of confirmation. Adverse effects of chemotherapy were checked every month during the therapy. The most recent date was the last day of December 2004. The median follow-up period was 91 months. The presence or absence of any recurrence was determined according to our follow-up protocol consisting of a physical examination including digital examination every 2-3 months, measurement of serum tumour marker (carcinoembryonic antigen, CEA) level every 2-3 months, and/or by findings on barium enema or colonoscopy every 1-2 years, chest radiography every 6 months, and abdominal ultrasound (US), abdominal-computed tomography (CT) or abdominal magnetic resonance imaging (MRI) every 6 months up to 5 years, and according to a modified protocol case-by-case thereafter.

Immunohistochemistry. After an initial review of all available hematoxylin and eosin-stained (H\&E) slides of the surgical specimens consisting of 342 primary tumours, 13 recurrent liver tumours and 6 recurrent lung tumours, we selected two paraffin blocks from each tumour, in which the invasive front edge and the viable tumour were clearly revealed. Serial 4micron sections were recut from each block. One section from each block was stained by H\&E again, a second was immunostained for VEGF. Immunostaining was performed using the avidin-biotin peroxidase complex method. Antihuman VEGF rabbit polyclonal IgG (R\&D systems, Minneapolis, MN, USA) was used as the primary antibody. The primary antibody was detected using avidin-biotin peroxidase complex (Vector Laboratories, CA, USA) and 3, 3 '-diaminobenzidine tetrahydrochloride as the chromogen. These sections were also counterstained with hematoxylin and mounted. For negative control, the sections were incubated with non-immune IgG in place of the primary antibody.

Statistical analysis. The background of the patients, the incidence and the mode of recurrence, and overall survival rate and disease-free survival rate analyzed by the Kaplan-Meier method, were compared between the chemotherapy group and the surgery-alone group. Multivariate analysis for the factors related to disease-free survival and overall survival was also carried out using Cox's proportional hazard model. All data were compiled and analyzed by statistical analysis software version 6.12 (SAS Institute, Cary, NC, USA). The differences in clinico-pathological characteristics between the two groups 


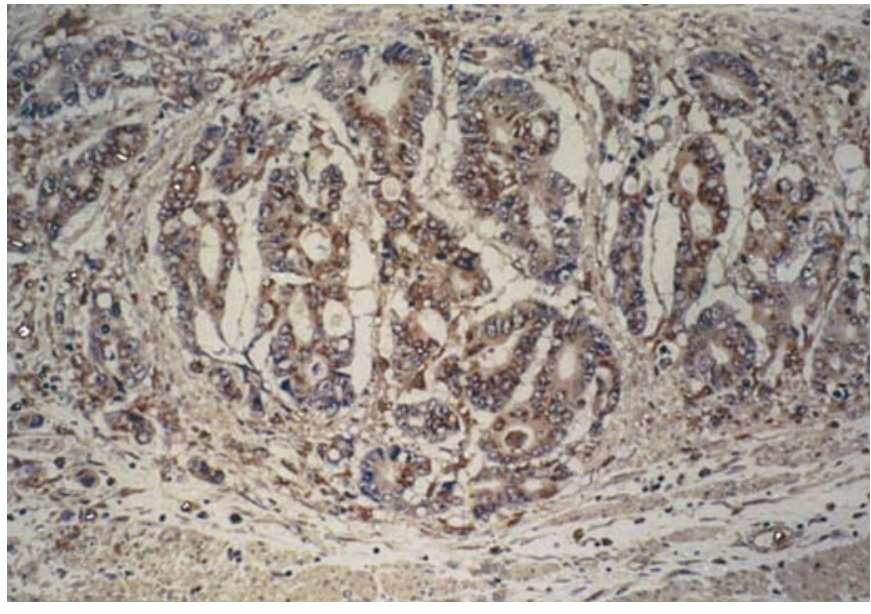

Figure 1. Immunostaining for VEGF in colorectal cancer tissue. VEGF observed in the cytoplasm of tumour cells as supranuclear staining. Original magnification of $\mathrm{x} 100$.

were assessed for statistical significance using the Chi-square test, Fisher's exact test, and Student's t-test. Differences between the groups in Kaplan-Meier plots were evaluated using the log-rank test.

\section{Results}

Background of patients. The background of patients and their tumours between the chemotherapy group and the surgeryalone group is summarized in Table I. The average age in the surgery-alone group was significantly higher than that in the chemotherapy group. However, there was no significant difference in sex, distribution of tumour stage, tumour location, $\mathrm{N}$ factor, incidence of tumour invasion to adjacent organs, lymphatic invasion, or venous invasion, between the two groups.

Immunoexpression of VEGF in primary colorectal cancer tissues. VEGF was expressed mainly in the cytoplasm of cancer cells (Fig. 1), and in the cytoplasm of a few neutrophilic leucocytes, monocytes-macrophages, and fibroblast cells. A sample with positive staining for VEGF in $>10 \%$ of all tumour cells was defined as positive (positive cell ratio was $>50 \%$ in most cases whose tumour cells were stained for VEGF) (12). Forty-eight percent of all primary colorectal tumours were positive for VEGF expression.

Correlation between the VEGF expression in primary tumour and recurrent tumour cells. Among 19 patients with recurrence to the liver or the lung which could be resected postoperatively, VEGF was positively expressed by the cancer cells in 12 primary and in 13 recurrent tumours. In 11 of 12 patients with primary tumours positive for VEGF, recurrent tumour cells also were positive for VEGF. There was a positive correlation $(\mathrm{p}=0.010)$ in VEGF expression between the primary and recurrent tumours (Table II).

Multivariate analysis for disease-free survival rate and overall survival rate. Various factors such as post-operative adjuvant chemotherapy, tumour location (colon vs. rectum), histological
Table II. Correlation of the VEGF expression between the primary and recurrent tumours.

VEGF expression in the recurrent tumours

Negative Positive Total

\begin{tabular}{lllll}
$\begin{array}{l}\text { VEGF expression in } \\
\text { the primary tumours }\end{array}$ & Negative & 5 & 2 & 7 \\
& Positive & 1 & 11 & 12 \\
& Total & 6 & 13 & 19 \\
\hline
\end{tabular}

$\mathrm{p}=0.010$ (Chi-square value was 8.146).

Table III. Multivariate analysis for the factors correlated to the disease-free survival and the overall survival rate.

\begin{tabular}{lccc}
\hline Variable & $\mathrm{p}$-value & $95 \% \mathrm{CI}$ & $\begin{array}{c}\text { Hazard } \\
\text { ratio }\end{array}$ \\
\hline $\begin{array}{l}\text { Disease-free survival rate } \\
\text { Venous invasion (+) }\end{array}$ & $\mathrm{p}=0.0001$ & $1.497-3.534$ & 2.299 \\
Stage III & $\mathrm{p}=0.0066$ & $1.193-2.967$ & 1.883 \\
VEGF (+) & $\mathrm{p}=0.0199$ & $1.085-2.564$ & 1.667 \\
Overall survival rate & & & \\
Stage III & $\mathrm{p}=0.0018$ & $1.381-4.082$ & 2.375 \\
Venous invasion $(+)$ & $\mathrm{p}=0.0034$ & $1.274-3.378$ & 2.075 \\
Surgery-alone & $\mathrm{p}=0.0405$ & $1.022-2.707$ & 1.664 \\
VEGF (+) & $\mathrm{p}=0.0453$ & $1.010-2.695$ & 1.650 \\
\hline
\end{tabular}

tumour grade (well-differentiated adenocarcinoma vs. others), tumour invasion to adjacent organs (- vs. +), pathological tumour stage (II vs. III), N factor (N0-1 vs. N2), lymphatic invasion (ly- vs. ly+) (16), venous invasion (v- vs. v+) (17), age, sex, and VEGF expression (- vs. +) were each evaluated for their independent contributions to the disease-free survival and the overall survival rate after operation using Cox's proportional hazards model. The positive VEGF expression was a significantly worse factor for recurrence, and the surgery-alone and the positive VEGF expression were a significantly worse factor for death, in addition to the stage III and the presence of venous invasion (Table III).

Relationship between the VEGF expression and the clinicopathological factors. The relationships between the VEGF expression and the clinico-pathological factors are shown in Table IV. There was no significant correlation between the VEGF expression and the clinico-pathological factors including tumour location, lymph node metastasis and number of lymph node metastasis, tumour invasion to adjacent organs, lymphatic invasion, venous invasion, or histological grade of tumour. 
Table IV. VEGF expression and clinico-pathological factors.

Factor $\begin{gathered}\text { VEGF expression }(\%) \quad \text { p-value } \\ \text { (positive cases/ all cases) }\end{gathered}$

\section{Sex}

Male

$100 \quad / 210$

Female

$65 \quad / 150$

Location

Colon

$98 \quad / 192$

Rectum

65

$/ 150$

$\mathrm{N}$ factor (stage)

N0 (stage II)

$67 \quad / 156$

N1-2 (stage III)

$96 \quad / 186$

Tumour invasion

to adjacent organs
(-)

$144 \quad / 303$
(+)

$19 / 39$

Lymphatic invasion

$\begin{array}{lll}\text { ly (-) } & 81 & / 186 \\ \text { iy }(+) & 82 & / 156\end{array}$

Venous invasion

$\begin{array}{lll}\mathrm{v}(-) & 98 & / 204 \\ \mathrm{v}(+) & 65 & / 138\end{array}$

$\begin{array}{lll}\text { Histology } & & \\ \text { Well } & 97 & / 210 \\ \text { Others } & 66 & / 132\end{array}$

Lymphatic and venous invasion were graded according to the Shirouzu's criteria. Well, well differentiated adenocarcinoma.

Disease-free survival and overall survival rate based on the VEGF expression. The disease-free survival rate in patients with a tumour positive for VEGF was significantly lower than that in patients negative for VEGF, and the overall survival rate in patients with a tumour positive for VEGF tended to be lower than that in patients negative for VEGF (Fig. 2).

Disease-free survival and overall survival rate based on adjuvant chemotherapy. In both groups, the major mode of recurrence was hematogenous metastasis, and no difference in the pattern of recurrence was found between the two groups (data not shown). The disease-free survival and the overall survival rate in the chemotherapy group were higher than those in the surgery-alone group, although not significantly (Fig. 3).

However, when the disease-free survival rates were stratified according to the prognostic factors demonstrated by the multivariate analysis such as the pathological stage (Fig. 4), the venous invasion, and the VEGF expression, then no significant difference in the disease-free survival rate was found between the chemotherapy group and the surgery-alone group in a tumour with venous invasion ( $\mathrm{p}=0.523$ ) (Fig. 5), or
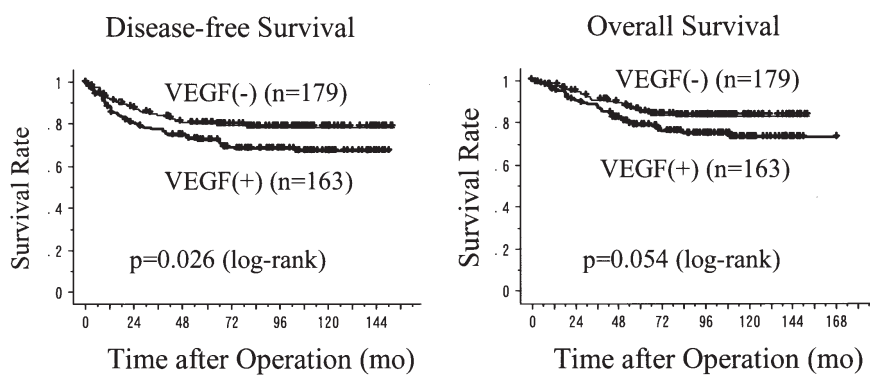

Figure 2. The disease-free survival curves according to VEGF expression. The disease-free survival rate $(\mathrm{p}=0.026)$ and the overall survival rate $(p=0.054)$ in patients with a tumour positive for VEGF were lower than those negative for VEGF.
Disease-free Survival

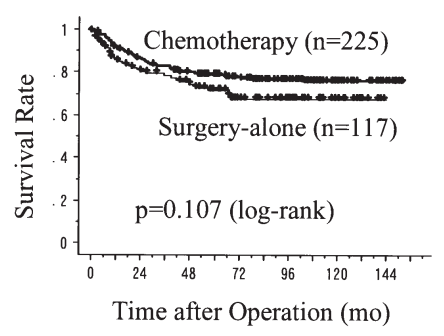

Overall Survival

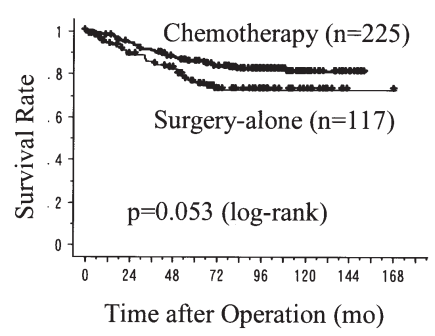

Figure 3. The disease-free survival and the overall survival curves according to post-operative adjuvant chemotherapy. The disease-free survival rate $(p=0.107)$ and the overall survival rate $(p=0.053)$ in the chemo-therapy group tended to be higher than those in the surgery-alone group.
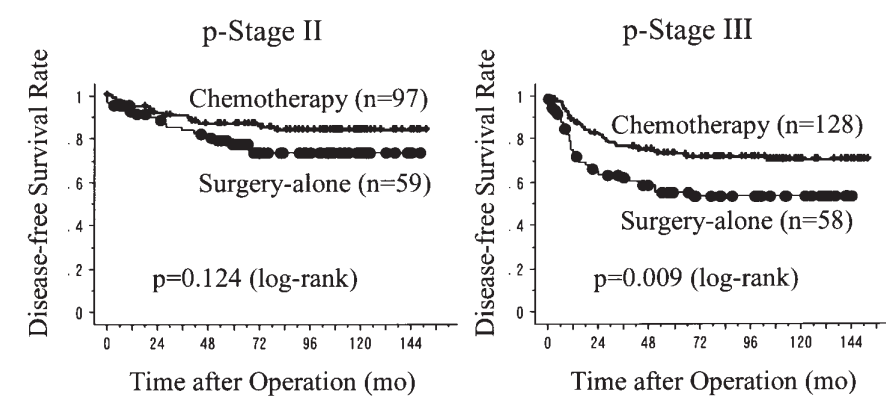

Figure 4. The disease-free survival curves according to post-operative adjuvant chemotherapy-stratified to the pathological stage. There was significant difference $(\mathrm{p}=0.009)$ in disease-free survival rate in stage III tumours between the chemotherapy group and the surgery-alone group, but not in stage II tumours ( $\mathrm{p}=0.124)$.

in a tumour positive for VEGF ( $\mathrm{p}=0.235)$ (Fig. 6), contrary to the significant difference in patients with a tumour negative for venous invasion ( $\mathrm{p}=0.002)$ (Fig. 5) or for VEGF $(\mathrm{p}=0.013)$ (Fig. 6).

\section{Discussion}

A recent meta-analysis has reported that post-operative oral fluoropyrimidines such as UFT and 5'-DFUR were more effective in patients with colorectal cancer at stage II or III than surgery alone $(5,6)$. Moreover, it has been shown that the post-operative adjuvant chemotherapy using capecitabine 

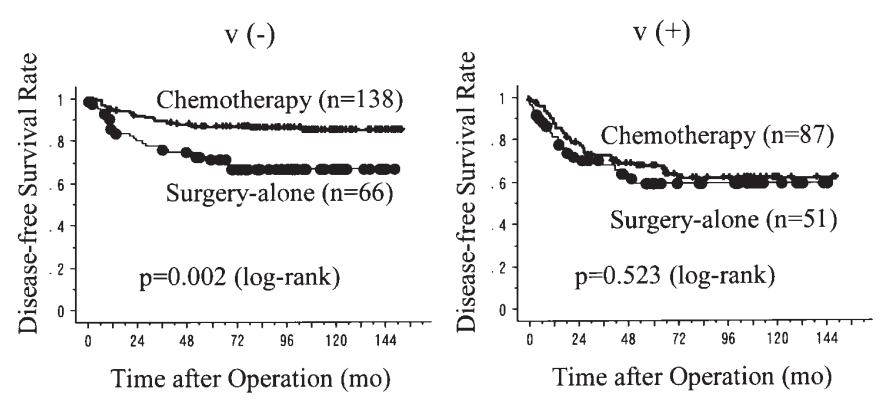

Figure 5. The disease-free survival curves according to post-operative adjuvant chemotherapy-stratified to the presence of venous invasion. There was significant difference $(\mathrm{p}=0.002)$ in disease-free survival rate in tumours without venous invasion between the chemotherapy group and the surgeryalone group, but not in tumours with venous invasion $(\mathrm{p}=0.523)$.
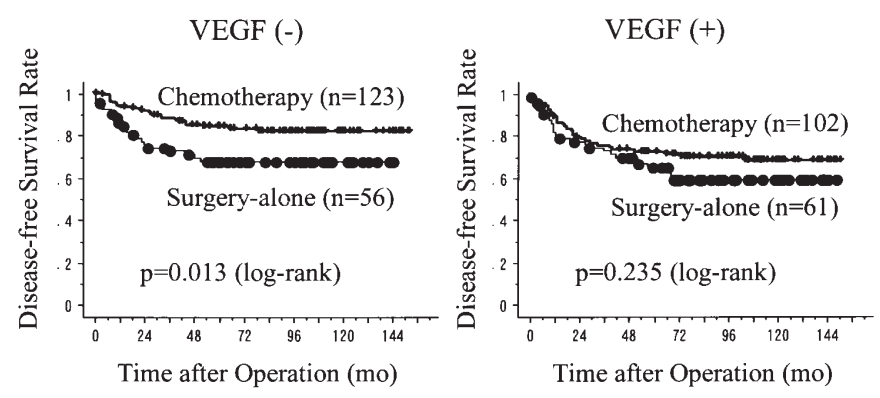

Figure 6 . The disease-free survival curves according to post-operative adjuvant chemotherapy-stratified to the VEGF immunoexpression. There was significant difference $(\mathrm{p}=0.013)$ in disease-free survival rate in tumours negative for VEGF between the chemotherapy group and the surgery-alone group, but not in tumours positive for $\operatorname{VEGF}(\mathrm{p}=0.235)$.

or UFT/oral LV is not inferior to bolus 5-FU/LV. In our retrospective study, the comparison of disease-free survival rate and overall survival rate, and the multivariate analyses supported the efficacy of post-operative adjuvant chemotherapy using oral fluoropyrimidines.

However, in biologically aggressive tumours with venous invasion, the adjuvant chemotherapy could not reduce the risk of recurrence. Our results also indicated that disease-free survival benefit of post-operative adjuvant chemotherapy using oral fluoropyrimidines did not reach significance in tumours positive for VEGF, contrary to the significant efficacy in tumours negative for VEGF. The retrospective and small sample number generally may have obscured the possible benefit. However, our results show that further investigation concerning molecular targeting therapy for VEGF is worthwhile. VEGF plays a key role in the development and progression of human malignancies including colorectal cancer. In particular, VEGF participates in the early stages of tumourigenesis and tumour growth including metastatic tumours. Thus, VEGF is attractive as a target for cancer treatment (18), and clinical application of the molecular targeting therapy alone or in combination with chemotherapeutic agents may be good adjuvant therapy after curative resection of the primary tumour in which VEGF activity is high and implicated in tumour progression and metastasis. Our multivariate analysis showed that VEGF expression was an independently significant factor for poor disease-free survival. The VEGF expression was suspected to be implicated in the development of post-operative recurrent tumours independently, indicating a target as post-operative adjuvant therapy. Moreover, the positive correlation of VEGF expression between the primary tumours and the recurrent liver or lung tumours indicated that VEGF was implicated in the development of post-operative recurrence even in a secondary organ. These results suggested that inhibition in the VEGF activity might prevent post-operative tumour growth and secondary spreading of micrometastases, in particular in tumours positive for VEGF.

With regard to the rationale for a combination of antiangiogenic drugs with chemotherapeutic agents, anti-angiogenic agents may improve the delivery of chemotherapeutic agents by altering the tumour vasculature and through decreasing the elevated interstitial pressure in tumours $(19,20)$. Moreover, conventional cytotoxic chemotherapeutics affect the endothelium of the growing tumour vasculature, and there is evidence that the anti-proliferative or pro-apoptotic actions of chemotherapeutic agents such as paclitaxel, cisplatinum, and adriamycin on human endothelial cells in culture are suppressed by the presence of VEGF $(21,22)$. A high local concentration of VEGF in the tumour microenvironment might therefore induce or promote multidrug resistance, by inducing a highly specific chemoprotective effect towards the VEGF receptor 2-positive endothelial cells of the tumour (21-23). Chemotherapy itself might also induce or up-regulate the expression of VEGF and other endothelialcell pro-survival growth factors in tumour cells (24). Therefore, the combination of a chemotherapeutic agent with a drug that blocks VEGF or its receptor might selectively amplify the pro-apoptotic effects of chemotherapeutic agents against activated endothelial cells (25). A randomized placebo-controlled phase III clinical study with bevacizumab (anti-VEGF antibody) in combination with intravenous 5FU/LV and irinotecan for advanced colorectal cancer demonstrated a statistically significant prolongation of survival, compared with only the chemotherapy regimen (15). Micrometastasis would be also a good candidate for molecular targeting therapy to VEGF in combination with 5FU-based chemotherapy as post-operative adjuvant therapy in colorectal cancer. One of the proposed benefits of targeting therapies is the reduction of toxicity and improved QOL. However, when these drugs are combined with maximum tolerable doses of chemotherapy these benefits may not be realized. Anti-angiogenic drugs might also improve the efficacy of a continuous low-dose chemotherapy regimen such as oral fluoropyrimidines, for which the side effects would be much more tolerable, and the two types of drug such as bevacizumab and oral fluoropyrimidines could be administered together over a long period in a post-operative adjuvant setting.

Although a targeting therapy for VEGF may theoretically be effective in a VEGF overexpressing tumour such as trastuzumab (Herceptin) for human epidermal growth factor receptor 2 (HER2/neu) in breast cancer (26), it is not yet proven whether VEGF inhibitors are more effective in tumours positive for VEGF immunoexpression or its grade. Accordingly, any correlation between the VEGF expression 
and the efficacy of targeting therapy for VEGF should be investigated to clarify predictive factors for targeting therapy in terms of more effective therapy.

In conclusion, the efficacy of post-operative adjuvant chemotherapy using oral fluoropyrimidines such as UFT and 5'-DFUR may not be a good option for patients with a tumour positive for VEGF having a greater risk of postoperative recurrence. Further investigation is recommend on the efficacy of targeting therapy for VEGF such as bevacizumab in combination with oral fluoropyrimidines as post-operative adjuvant therapy for colorectal cancer, in particular in tumours positive for VEGF.

\section{Acknowledgements}

This study was supported by a Grant-in-Aid for Scientific Research (C) (No. 13671364) from the Ministry of Education, Culture, Sports, Science and Technology of Japan.

\section{References}

1. Greenlee RT, Murray T, Bolden S and Wingo PA: Cancer Statistics, 2000. CA Cancer J Clin 50: 7-33, 2000.

2. International Multicentric Pooled Analysis of Colon Cancer Trials (IMPACT) investigators: Efficacy of adjuvant fluorouracil and folinic acid in colon cancer. Lancet 345: 939-944, 1995.

3. International Multicentric Pooled Analysis of B2 Colon Cancer Trials (IMPACT B2) investigators: Efficacy of adjuvant fluorouracil and folinic acid in B2 colon cancer. J Clin Oncol 17: 1356-1363, 1999.

4. Andre T, Boni C, Mounedji-Boudiaf L, Navarro M, Tabernero J, Hickish T, Topham C, Zaninelli M, Clingan P, Bridgewater J, Tabah-Fisch I and De Gramont A: Multicenter International Study of Oxaliplatin/5-Fluorouracil/Leucovorin in the Adjuvant Treatment of Colon Cancer (MOSAIC) investigators: Oxaliplatin, fluorouracil, and leucovorin as adjuvant treatment for colon cancer. N Engl J Med 350: 2343-2351, 2004.

5. Sakamoto J, Hamada C, Kodaira S, Nakazato H and Ohashi Y: Adjuvant therapy with oral fluoropyrimidines as main chemotherapeutic agents after curative resection for colorectal cancer: individual patient data meta-analysis of randomized trials. Jpn J Clin Oncol 29: 78-86, 1999

6. Meta-Analysis Group of the Japanese Society for Cancer of the Colon and Rectum and the Meta-Analysis Group in Cancer: Efficacy of oral adjuvant therapy after resection of colorectal cancer: 5-year results from three randomized trials. J Clin Oncol 22: 484-492, 2004.

7. Saltz LB, Cox JV, Blanke C, Rosen LS, Fehrenbacher L, Moore MJ, Maroun JA, Ackland SP, Locker PK, Pirotta N, Elfring GL and Miller LL: Irinotecan plus fluorouracil and leucovorin for metastatic colorectal cancer. Irinotecan Study Group. N Engl J Med 343: 905-914, 2000.

8. De Gramont A, Figer A, Seymour M, Homerin M, Hmissi A, Cassidy J, Boni C, Cortes-Funes H, Cervantes A, Freyer G, Papamichael D, Le Bail N, Louvet C, Hendler D, De Braud F, Wilson C, Morvan F and Bonetti A: Leucovorin and fluorouracil with or without oxaliplatin as first-line treatment in advanced colorectal cancer. J Clin Oncol 18: 2938-2947, 2000.

9. Hoff PM, Ansari R, Batist G, Cox J, Kocha W, Kuperminc M, Maroun J, Walde D, Weaver C, Harrison E, Burger HU, Osterwalder B, Wong AO and Wong R: Comparison of oral capecitabine versus intravenous fluorouracil plus leucovorin as first-line treatment in 605 patients with metastatic colorectal cancer: results of a randomized phase III study. J Clin Oncol 19: 2282-2292, 2001 .

10. Ferrara N, Gerber HP and LeCouter J: The biology of VEGF and its receptors. Nat Med 9: 669-676, 2003.

11. Kondo Y, Arii S, Mori A, Furutani M, Chiba T and Imamura M: Enhancement of angiogenesis, tumour growth, and metastasis by transfection of vascular endothelial growth factor into LoVo human colon cancer cell line. Clin Cancer Res 6: 622-630, 2000 .
12. Harada Y, Ogata Y and Shirouzu K: Expression of vascular endothelial growth factor and its receptor KDR (kinase domaincontaining receptor)/Flk-1 (fetal liver kinase-1) as prognostic factors in human colorectal cancer. Int J Clin Oncol 6: 221-228, 2001.

13. Kabbinavar F, Hurwitz HI, Fehrenbacher L, Meropol NJ, Novotny WF, Lieberman G, Griffing S and Bergsland E: Phase II, randomized trial comparing bevacizumab plus fluorouracil (FU)/ leucovorin (LV) with FU/LV alone in patients with metastatic colorectal cancer. J Clin Oncol 21: 60-65, 2003.

14. Yang JC, Haworth L, Sherry RM, Hwu P, Schwartzentruber DJ, Topalian SL, Steinberg SM, Chen HX and Rosenberg SA: A randomized trial of bevacizumab, an anti-vascular endothelial cell growth factor antibody, for metastatic renal cancer. N Engl J Med 349: 427-434, 2003.

15. Hurwitz H, Fehrenbacher L, Novotny W, Cartwright T, Hainsworth J, Heim W, Berlin J, Baron A, Griffing S, Holmgren E, Ferrara N, Fyfe G, Rogers B, Ross R and Kabbinavar F: Bevacizumab plus irinotecan, fluorouracil, and leucovorin for metatatic colorectal cancer. N Engl J Med 350: 2335-2342, 2004

16. Shirouzu K, Isomoto H, Morodomi $\mathrm{T}$ and Kakegawa $\mathrm{T}$ : Carcinomatous lymphatic invasion: prognostic significance in patients with rectal carcinoma - a long-term prospective study. Cancer 75: 4-10, 1995.

17. Shirouzu K, Isomoto $H$, Kakegawa $T$ and Morimatsu M: A prospective clinicopathologic study of venous invasion in colorectal cancer. Am J Surg 162: 216-222, 1991.

18. Morgan B, Thomas AL, Drevs J, Hennig J, Buchert M, Jivan A, Horsfield MA, Mross K, Ball HA, Lee L, Mietlowski W, Fuxuis S, Unger C, O'Byrne K, Henry A, Cherryman GR, Laurent D, Dugan M, Marme D and Steward WP: Dynamic contrast-enhanced magnetic resonance imaging as a biomarker for the pharmacological response of PTK787/ZK 222584, an inhibitor of the vascular endothelial growth factor receptor tyrosine kinases, in patients with advanced colorectal cancer and liver metastases: results from two phase I studies. J Clin Oncol 21: 3955-3964, 2003 .

19. Jain RK: Normalizing tumour vasculature with anti-angiogenic therapy: a new paradigm for combination therapy. Nat Med 7: 987-989, 2001.

20. Willett CG, Boucher Y, Di Tomaso E, Duda DG, Munn LL, Tong RT, Chung DC, Sahani DV, Kalva SP, Kozin SV, Mino M, Cohen KS, Scadden DT, Hartford AC, Fischman AJ, Clark JW, Ryan DP, Zhu AX, Blaszkowsky LS, Chen HX, Shellito PC, Lauwers GY and Jain RK: Direct evidence that the VEGFspecific antibody bevacizumab has antivascular effects in human rectal cancer. Nat Med 10: 145-147, 2004

21. Sweeney CJ, Miller KD, Sissons SE, Nozaki S, Heilman DK, Shen J and Sledge GW Jr: The anti-angiogenic property of docetaxel is synergistic with a recombinant humanized monoclonal antibody against vascular endothelial growth factor or 2 -methoxyestradiol but antagonized by endothelial growth factors. Cancer Res 61: 3369-3372, 2001.

22. Tran J, Master Z, Yu JL, Rak J, Dumont DJ and Kerbel RS: A role for survivin in chemoresistance of endothelial cells mediated by VEGF. Proc Natl Acad Sci USA 99: 4349-4354, 2002.

23. Castilla MA, Caramelo C, Gazapo RM, Gonzalez-Pacheco FR, Martin O, Tejedor A, Bragado R and Arroyo MV: Role of vascular endothelial growth factor (VEGF) in endothelial cell protection against cytotoxic agents. Life Sci 67: 1003-1013, 2000.

24. Gorski DH, Beckett MA, Jaskowiak NT, Calvin DP, Mauceri HJ, Salloum RM, Seetharam S, Koons A, Hari DM, Kufe DW and Weichselbaum RR: Blockage of the vascular endothelial growth factor stress response increases the anti-tumour effects of ionizing radiation. Cancer Res 59: 3374-3378, 1999.

25. Klement G, Baruchel S, Rak J, Man S, Clark K, Hicklin DJ, Bohlen P and Kerbel RS: Continuous low-dose therapy with vinblastine and VEGF receptor-2 antibody induces sustained tumour regression without overt toxicity. J Clin Invest 105: R15-R24, 2000.

26. Vogel CL, Cobleigh MA, Tripathy D, Gutheil JC, Harris LN, Fehrenbacher L, Slamon DJ, Murphy M, Novotny WF, Burchmore M, Shak S, Stewart SJ and Press M: Efficacy and safety of trastuzumab as a single agent in first-line treatment of HER2-overexpressing metastatic breast cancer. J Clin Oncol 20: 719-726, 2002. 